\title{
RELATIONS BETWEEN PHYSICAL ACTIVITY, FITNESS, MUSCLE STRENGTH AND HEALTH: FINDINGS FROM THE EUROPEAN YOUTH HEART STUDY (EYHS)
}

\author{
Karsten Froberg \\ University of Southern Denmark, Odense, Denmark
}

\begin{abstract}
The European Youth Heart Study (EYHS) is an on-going multi-centre, prospective, observational cohort study. High quality observational data from population-based samples followed over time provide a valuable source that can be used for examining hypotheses of associations of suspected risk factor exposures with health outcomes. Furthermore, given that the data are collected in well-defined population samples with high participation rates, it can be used for surveillance purposes. Surveillance involves a systematic collection of data from well-defined populations, and analysis and interpretation of such data. Timely collected- and high quality data from population-based samples is a crucial resource that can inform policy-makers and the public, and is vital for health care authorities for timely planning of prevention programs.

The EYHS has used standardized high quality methods to obtain CVD risk factor levels and their determinants among population-based samples of children and adolescents across Europe. It involves random population-based samples of children and adolescents recruited from distinct geographical regions in Europe, which are followed over time. Since the late 1990-ies the EYHS has collected detailed data on 6580 children, adolescents, and young adults with high response rates (overall response rate of $72 \%$ ). These data have been widely used for describing population distribution of early determinants of cardiovascular risk factors and sources of their inequalities, and in identifying personal, genetic, and environmental determinants of current and young adulthood cardiovascular health outcomes.

This article summarizes major findings related to sedentary behaviour, physical activity and physical fitness. The findings include cross-sectional and prospective observational data from the EYHS.
\end{abstract}

Keywords: children, physical activity, sedentary behaviour, cardiovascular fitness.

\section{INTRODUCTION}

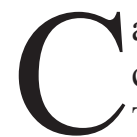
ardiovascular diseases are the leading cause of death in Europe (Nichols, Townsend, Scarborough, \& Rayner, 2013), and the societal and economic burden of these diseases continues to be enormous. While marked improvements in mortality from cardiovascular disease have occurred over the last three decades in most Northern- and Western European countries, many Central- and Eastern European countries show less progress in combating these diseases (Nichols et al., 2013). Both within and between country inequalities are likely to be dynamic and vary over time and monitoring environmental, behavioural, and biological cardiovascular disease risk factor levels in children and adolescents is an important outset for addressing the future disease burden in Europe. Regional- and national inequalities are likely to be present and comprise a key future public health challenge in Europe.

Although the majority of cardiovascular diseases manifest in adulthood, their origins begin in utero or childhood. Autopsy investigations indicate that the earliest type of lesions (fatty streaks) can be identified in large arteries as early as during fetal life, and the majority of children are affected during the first decade. Growth and 
maturation during childhood coincide with major changes in health behaviours and biological risk factor levels, and have important links to current and adult cardiovascular health ( Ekelund et al., 2009; Laitinen et al., 2012). Well known biological risk factors include obesity, raised blood pressure, and impaired glucose homeostasis. While the influence of lifestyle behaviours such as smoking, physical activity, and diet on these biological risk factors in childhood have been studied in some detail, the magnitude of associations, detailed dose-response relationships and the influence of other factors such as chemicals with endocrine disrupting abilities, genetic variation, metabolites, and their interaction with lifestyle behaviours remain largely unknown. Furthermore, assessment of lifestyle exposures such as physical activity with better methods (e. g. using multi-censor accelerometry) in large cohorts of children and adolescents followed into adulthood are required to improve our understanding of such factors influence on cardiovascular risk from childhood to adulthood. Collecting surveillance data on cardiovascular risk factors and further elucidating what determines cardiovascular health in childhood through adulthood are vital for prioritizing public health policy and action for primordial prevention of cardiovascular disease (defined as prevention of the development of risk factors in the first place) in Europe.

\section{AIMS AND METHODS}

The European Youth Heart Study (EYHS) is a multi-centre, prospective, observational cohort study of diverse population-based samples of children and adolescents from distinct geographical regions in Europe. The study was initiated in the late 1990-ies with the overall aim to identify the foundations of cardiovascular disease risk in the first decades of life.

Using standardized high quality methods to obtain CVD risk factor levels and their determinants among population-based samples of children and adolescents across Europe, the EYHS has collected detailed data on 6580 children, adolescents, and young adults with high response rates (overall response rate of $72 \%$ ). At each study location, a proportional two-stage cluster sample of children and adolescents has been carried out (around 1000 children in each sample). The primary sampling unit was a complete list of schools in the area (e. g. the municipality). Each school was given a weighting according to the number of children enrolled, and at each study location a minimum of 20 schools was be randomly selected using probability proportional to school size. The secondary sampling unit were children and adolescents enrolled in these schools.

The first centres involved were in Denmark, Portugal (Madeira), Norway and Estonia. Later Iceland and Spain joined the study. The assessments started in 1997 studying 9 and 15 year old children of both gender. A 6- and 12-year follow-up have been finished in Denmark and Madeira, 6-year follow-up in Norway and Iceland.

Sedentary and physical activity behaviours were objectively assessed with accelerometers. Blood samples were drawn for analysis of traditional CVD risk factors, genetic mapping and a possibility to analyse new biomarkers. Assessments also included measurements of dietary intake, physical fitness including cardio-respiratory fitness (CRF), muscular strength, skinfold measurements and a comprehensive questionnaire for both children and parents. New measures have been included, e. g. ultrasound of the carotid artery to measure arterial stiffness and intima-media thickness (in Denmark). Main outcomes and determinants are given in Table 1.

The data have been widely used for describing population distribution of early determinants of cardiovascular risk factors and sources of their inequalities, and in identifying personal, genetic, and environmental determinants of current and young adulthood cardiovascular health outcomes (Lawlor et al., 2005; Ekelund et al., 2006; Froberg \& Andersen, 2005; Kelliny et al., 2009; Barker et al., 2011; Ekelund et al., 2009; Ong et al., 2009; den Hoed et al., 2010; Grøntved et al., 2013; Grøntved et al., 2014).

This article summarizes the major findings related to sedentary behaviour, physical activity and physical fitness. The findings include crosssectional and prospective observational data from the EYHS.

\section{SEDENTARY BEHAVIOUR}

During the past decades the increase of sedentary behaviours, such as television watching and playing electronic games, may have contributed to increase the incidence of metabolic and CVD risk factors in children, including disturbed insulin and glucose metabolism, hypertension, general and abdominal obesity, and dyslipidaemia. 


\begin{tabular}{|c|c|c|}
\hline \multirow{20}{*}{$\begin{array}{l}\text { Table. Main cardiovascular } \\
\text { outcomes and determinants } \\
\text { that have been assessed in the } \\
\text { EYHS }\end{array}$} & Cardiovascular health outcomes & Cardiovascular health determinants (cont) \\
\hline & Obesity & \multirow{11}{*}{$\begin{array}{l}\text { Muscle strength } \\
\text { Cardiorespiratory fitness } \\
\text { Leptin } \\
\text { Adiponectin } \\
\text { Family history of diseases } \\
\text { Early life determinants } \\
\quad \text { Birth weight } \\
\text { Maternal lifestyle during pregnancy } \\
\text { Soco-demographic determinants } \\
\text { Socioeconomic status of parents } \\
\text { Geographical region }\end{array}$} \\
\hline & Blood pressure & \\
\hline & Arterial stiffness & \\
\hline & Triglyceride & \\
\hline & HDL cholesterol & \\
\hline & Total cholesterol & \\
\hline & Glucose & \\
\hline & Insulin & \\
\hline & $\mathrm{HbAlc}$ & \\
\hline & & \\
\hline & Cardiovascular health determinants & \\
\hline & \multirow{8}{*}{$\begin{array}{l}\text { Physical activity } \\
\text { Smoking } \\
\text { Diet } \\
\text { Alcohol intake } \\
\text { Metabolites in urine and blood } \\
\text { Endocrine disrupting chemicals in urine } \\
\text { and blood }\end{array}$} & Ethinicity \\
\hline & & Gender \\
\hline & & Living conditions \\
\hline & & Marital status \\
\hline & & \\
\hline & & $\begin{array}{l}\text { Other health outcomes/determinants } \\
\text { Well-being }\end{array}$ \\
\hline & & Depression \\
\hline & & Cognitive function \\
\hline
\end{tabular}

A cross-sectional analysis of data from the EYHS, revealed that, on average, European children spent $262 \mathrm{~min} /$ day in sedentary activity (van Sluijs, Page, Ommundsen, \& Griffin, 2010) [van Sluijs, 2010 \#2135]. Additionally, sedentary time increased substantially with increasing age, indicating that early intervention is needed to prevent this increase and the development of health problems associated with sedentary behaviour. Since sedentary activity is associated with a variety of behavioural and social factors, and associations are different for different countries, a single strategy aimed at reducing time spent in sedentary activity in youth is therefore unlikely to be effective across Europe as the target populations and behaviours of focus differ between countries (van Sluijs et al., 2010)[van Sluijs, 2010 \#2135]. No associations with percent time sedentary were observed, suggesting that correlates associated with sedentary behaviour is likely to differ from those associated with physical activity (Nilsson et al., 2009). Besides environment factors, it has been hypothesized that sedentary behaviour may be related to lower birth weight. Data from the different centres of the EYHS showed that birth weight did not affect sedentary behaviour (Ridgway et al., 2011 c).

Major dimensions of sedentary behaviour are TV viewing and computer games. Children and adolescents that have more autonomy over their own behaviour are more likely to watch more than
$2 \mathrm{~h}$ of TV after school and spend more than an hour per day playing computer game (Jago et al., 2008 a). This TV viewing behaviour was associated with adiposity (Ekelund et al., 2006). However, after adjustment for physical activity and other covariates, the association of TV viewing with clustered metabolic risk (the sum of four skin folds, hypertension (average of systolic blood pressure and diastolic blood pressure), hyperglycaemia (fasting plasma glucose), insulin resistance (fasting insulin), inverted fasting HDL cholesterol, and hypertriglyceridemia) was no longer significant. These results suggest that TV viewing and physical activity may be separate entities and differently associated with adiposity and metabolic risk. The association between TV viewing and clustered metabolic risk was mediated by adiposity, whereas physical activity was associated with individual and clustered metabolic-risk indicators independently of obesity. As illustrated in figure 1, time spent sedentary was significantly and positively associated with fasting insulin and HOMA-IR in healthy Portuguese children after adjusting for total or central fat mass as measured with DXA, and time spent in moderate- and vigorous-intensity physical activity (MVPA) and overall physical activity (Sardinha, Baptista, \& Ekelund, 2008 a).

Adjusted geometric means of HOMA-IR stratified by quartiles of time spent sedentary ( $\mathrm{p}$ for trend $=.043$ ) and time spent at MVPA 


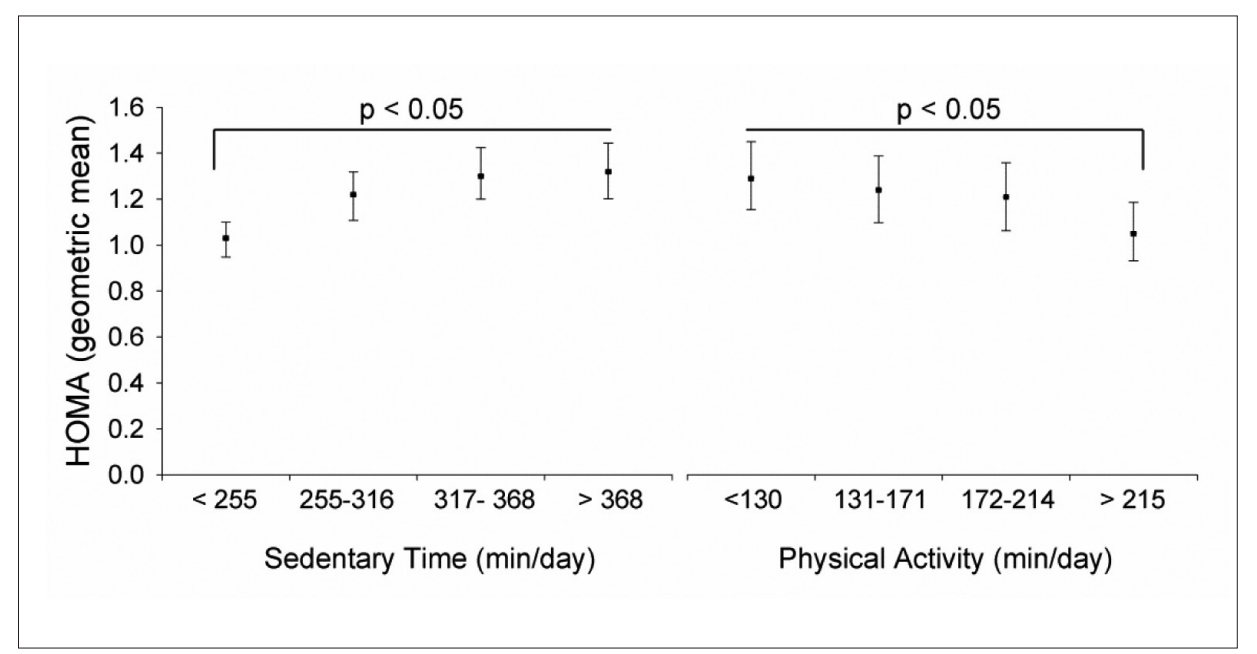

Figure 1. Adjusted geometric means of HOMA-IR stratified by quartiles of time spent sedentary ( $p$ for trend $=.043)$ and time spent at MVPA (p for trend $=.11$ ) in 9- to 10-year-old Portuguese children $(\mathrm{n}=308)$. Post hoc analyses revealed significant differences $(p<.05)$ between the first and fourth quartile for time spent sedentary and at moderate and vigorous intensity. Data are adjusted for sex, sexual maturity, birth weight, and fat mass. Adapted from (Sardinha et al., 2008 a)

( $\mathrm{p}$ for trend $=.11$ ) in 9- to 10-year-old Portuguese children $(\mathrm{n}=308)$. Post hoc analyses revealed significant differences $(\mathrm{p}<.05)$ between the first and fourth quartile for time spent sedentary and at moderate and vigorous intensity. Data are adjusted for sex, sexual maturity, birth weight, and fat mass. Adapted from (Sardinha et al., 2008 a).

A prospective cohort study among Danish men and women, followed for up to 12 years, revealed that $\mathrm{TV}$ viewing and total screen time in adolescence were positively associated with adiposity, triglycerides, and metabolic syndrome z-score in young adulthood. Individuals who increased their TV viewing, computer use, or total screen time with more than 2 hours/day from adolescence to young adulthood had 0.90, 0.95, and $1.40 \mathrm{~kg} / \mathrm{m}^{2}$ higher body mass index, respectively, in young adulthood compared with individuals who remained stable or decreased their viewing time. Insulin and metabolic syndrome z-scores were also higher among individuals who increased their TV viewing, computer use, or total screen time more than 2 hours/day compared with individuals who remained stable or decreased their viewing time (Grontved et al., 2013).

Taken together, cross-sectional and longitudinal findings suggest that screen-viewing behaviours of the entire family are likely to be important for changing youth screen-viewing. Preventive action against obesity and metabolic risk in children may need to target TV viewing and physical activity separately.

But new data show children can be sedentary and healthy in a cardiometabolic perspective. A paper from Ekelund et al. (2012) examining the independent and combined association between objectively measured time in moderate-to vigorousintensity physical activity (MVPA) and sedentary time with CVD risk factors in pooled data from 14 studies between 1998 and 2008 comprising 20871 children aged 4-18 years from the International Children's Accelerometry Database (including EYHS data) showed that time in MVPA was significantly associated with all CVD outcomes independent of sex, age monitor wear time, time spend sedentary and waist circumferences. Sedentary time was not associated with any outcome independent of time in MVPA; but in combined analyses, higher levels of MVPA were associated with better CVD risk factors across tertiles of sedentary time. The conclusion was that higher MVPA time by children and adolescents was associated with better CVD risk factors regardless of the amount of sedentary time.

Therefore, the development and implementation of multidimensional strategies focused on especially increasing overall involvement in different types of moderate-intensity activity are critically important in the primary prevention of metabolic disorders in children in order to improve young adulthood health in combination with reducing sedentary time.

\section{PHYSICAL ACTIVITY}

Lower birth weight has been associated with reduced physical performance, including muscle strength, muscle endurance and aerobic fitness in both childhood and adulthood and it has been suggested that this lower physical capacity may lead to reduced levels of physical activity. A survey using combined analysis of three European cohorts, 
indicated there was no evidence for an association between birth weight and total physical activity or time spent in MVPA (Ridgway et al., 2011 c). Overall there was no evidence for an association between birth weight and sedentary time. Further, higher birth weight was found to be associated with higher fat mass index and greater waist circumference, adjusted for sex, age-group, sexual maturity, height, and socioeconomic status. Lower birth weight was associated with higher fasting insulin only after further adjustment for adolescent waist circumference and body height (Ridgway et al., 2011 b). However, there was no evidence that physical activity or aerobic fitness can moderate the associations among higher birth weight and increased fat mass and metabolic risk in youth.

Influences on young peoples' physical activity are multi-factorial. A variety of psychological, social and physical environmental correlates of physical activity for young people have been identified. Data from a cross-sectional study among Norwegian boys and girls shows that there are psycho-social and environmental correlates of location-specific physical activity. Dependent of location (a) school commuting, b) informal games play at school and c) organized sport, structured exercise and games play in leisure time), psychosocial and environmental correlates explained between 15 and $55 \%$ of the variance in physical activity. The impact of peer support, enjoyment and perceived competence in physical activity generalized across the three locations. Enjoyment of physical education classes, parental support and teacher support, in contrast, confined to particular location-specific forms of physical activity. Generally, behavioural beliefs and environmental factors represented marginal correlates of all location-specific forms of activity (Ommundsen, Klasson-Heggelbo, \& Andersen, 2006). Frequency of outdoor play after school was found as a significant correlate for daily time in MVPA in 9-year-olds, while this correlate is attenuated in favour of participation in sport and exercise in clubs in 15-year-olds (Nilsson et al., 2009).

After adjustment for sex, study location, sexual maturity, birth weight, and parental BMI, time spent at MVPA and time ( $\mathrm{min} / \mathrm{d})$ spent at vigorous physical activity were independently associated with body fatness. Sex, study location, sexual maturity, birth weight, and parental BMI explained $29 \%$ of the variation in body fatness. Children who accumulated less than $1 \mathrm{~h}$ of moderate physical activity/d were significantly fatter than were those who accumulated more than $2 \mathrm{~h} / \mathrm{d}$. (Ekelund et al., 2004).

Clustering of CVD risk factors has recently proved a better measure of cardiovascular health in children than single risk factors. A crosssectional study of children from Denmark, Estonia, and Portugal reported that odds ratios for having clustered risk for ascending quintiles of physical activity were 3.29 (95\% CI 1.96-5.52), 3.13 (1.87-5.25), 2.51 (1.47-4.26), and 2.03 (1.183.50 ), respectively, compared with the most active quintile. Risk factors included in the composite risk factor score (mean of $\mathrm{Z}$ scores) were systolic blood pressure, triglyceride, total cholesterol/HDL ratio, insulin resistance, sum of four skinfolds, and aerobic fitness. The first to the third quintile of physical activity had a raised risk in all analyses. The mean time spent above 2000 counts per minute (cpm) in the fourth quintile was 116 min per day in 9-year-old and $88 \mathrm{~min}$ per day in 15-yearold children. It was found that, achieving $90 \mathrm{~min}$ of daily activity might be necessary for children to prevent insulin resistance, which seems to be the central feature for clustering of CVD risk factors (Andersen et al., 2006).

Figure 2 depicts the graded relationship between physical activity intensity quintiles and CVD Z-score.

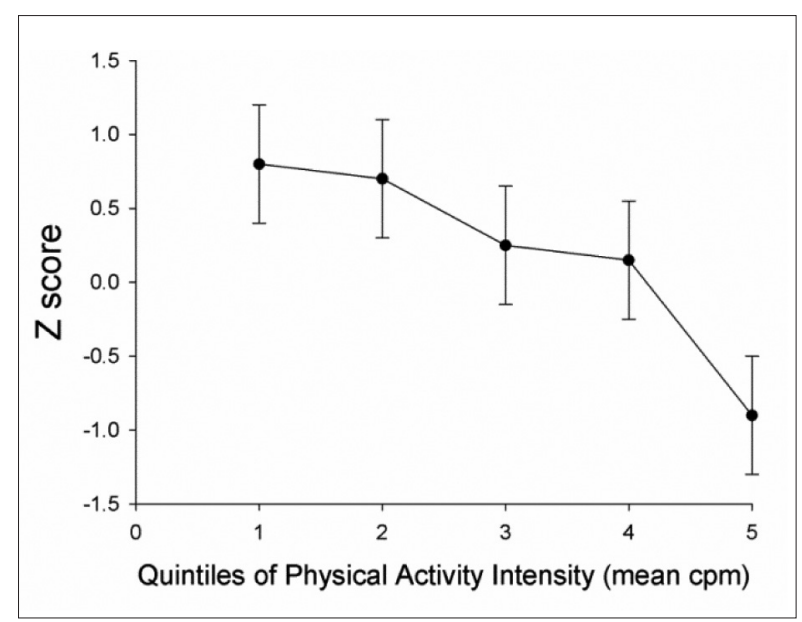

Figure 2. Mean $\mathbf{Z}$ score in the quintiles of average physical activity intensity. Vertical bars $=\mathbf{9 5} \%$ CI. Adapted from (Andersen et al., 2006: License permission 3153560906548; Content publisher: Elsevier; Content publication: The Lancet)

Further cross-sectional analysis showed that physical activity and CRF were separately and independently associated with individual and clustered metabolic risk factors in children (Ekelund et al., 2007). Total physical activity and 
all other subcomponents of physical activity were significantly associated with clustered metabolic risk. After excluding waist circumference from the summary score and further adjustment for waist circumference as a confounding factor, the magnitude of the association between CRF and clustered metabolic risk was attenuated, whereas the association with total physical activity was unchanged. In a recently accepted paper (RiedLarsen, Grontved, Froberg, Ehelund, \& Andersen, 2013) we observed that maintaining the adolescence MVPA level or increases herein was associated with lower arterial stiffness compared to the onces who decline. This association was independent of a range of confounders (incl. Tv-viewing, parental education, family history of CVD, soft drink and vegetable consumption). Furthermore, adiposity did not mediate that, suggesting that MVPA could have a preventive effect on the general population, not only the overweight. Besides being associated with the prevention of clustering of CVD risk factors, physical activity is an important predictor of health bone. Several previous studies in children and adolescents have reported positive associations between physical activity and bone density and architecture in boys and in girls. A cross-sectional study including Portuguese children demonstrated that vigorous intensity emerged as the main physical activity predictor of femoral neck strength but did not explain gender differences. Recommending daily vigorous physical activity for at least $\sim 25$ minutes seems to improve (10-14\%) femoral neck bone health in children (Sardinha et al., 2008 b).

Prospective observational analysis including 15-year old students from the Danish arm of the EYHS reported a physical activity declining from 45 minutes $>3000$ counts per minute in 1997 to 35 minutes $>3000$ counts per minute in 2003 (Jago et al., 2008 b). Longitudinal regression analyses showed that a change in minutes $>3000$ counts per minute was negatively associated with fasting insulin levels and HOMA-IR in 2003. Results demonstrated that a 6-year decline in physical activity was associated with higher insulin and HOMA-IR levels, suggesting that preventing an age-related decline in physical activity may be an effective means of preventing youth insulin resistance.

In conclusion, birth weight may not be an important biological determinant of habitual physical activity in children and adolescents. The accumulated amount of time spent at MVPA is related to body fatness in children; however, this relation is weak since the explained variance was less than $1 \%$. These data suggests that physical activity levels should be higher than the current international guidelines of at least 1 hour per day of physical activity of at least moderate intensity to prevent clustering of CVD risk factors. Vascular and bone health are improved by MVPA and more intense physical activity levels, respectively. Decrease in MVPA tends to have deleterious effects on biomarkers that are related to cardiovascular health and diabetes. These results suggest that fitness and activity affect metabolic risk through different pathways.

\section{PHYSICAL FITNESS}

Health-related fitness cut-offs for children and adolescents allow the identification of target populations for health promotion policies and disease prevention at early ages. CRF is easy and relatively cheap to measure, and yet it is an accurate tool for screening children with clustering of CVD risk factors. Lower birth weight was associated with lower CRF, after adjusting for sex, age group, country, sexual maturity and socioeconomic status, but introduction of fat free mass as a covariate in the model reduced the association between birth weight and CRF (Ridgway et al., 2011 a). Adegboye et al. (2011) defined optimal cutpoints for low CRF and evaluated its accuracy to predict clustering of risk factors for CVD in children and adolescents from EYHS. In girls, the optimal cut-offs for identifying individuals at risk were: $37.4 \mathrm{mlO}_{2} / \mathrm{min} / \mathrm{kg}$ (9-year-old) and $33.0 \mathrm{mlO}_{2} / \mathrm{min} /$ $\mathrm{kg}$ (15-year-old). In boys, the optimal cut-offs were $43.6 \mathrm{mlO}_{2} / \mathrm{min} / \mathrm{kg}$ (9-year-old) and $46.0 \mathrm{mlO}_{2} / \mathrm{min} /$ $\mathrm{kg}$ (15-year-old). Specificity (range 79.3-86.4\%) was markedly higher than sensitivity (range 29.7$55.6 \%$ ) for all cut-offs. Positive predictive values ranged from $19 \%$ to $41 \%$ and negative predictive values ranged from $88 \%$ to $90 \%$. The diagnostic accuracy for identifying children at risk, measured by the area under the curve, was significantly higher than what would be expected by chance for all cut-offs. We also observed that boys with a higher CRF (just above this cut point) had lower arterial fitness compared to the least fit boys (RiedLarsen et al., 2013).

Results from 9- and 15-year-olds from Denmark reported that physical fitness was weakly related to single CVD risk factors except sum of skinfolds where the relationship was strong (Wedderkopp 
et al., 2003). Low fitness increased the risk of having three or more CVD risk factors. An OR of 24.1 was found in the low fit group. Children and adolescents from Denmark, Portugal, Estonia, and Norway demonstrates a curvilinear relation between CRF and health parameters, including waist circumference, skinfolds, and blood pressure (Klasson-Heggebo et al., 2006). Additionally, Anderssen et al. (2007) reveal a strong association between CRF and the clustering of CVD risk factors, as described earlier by Wedderkopp, Froberg, Hansen, Riddoch and Andersen (2003). The OR for clustering in each quartile of fitness, using the quartile with the highest fitness as reference, were 13.0, 4.8, and 2.5, respectively, after adjusting for country, age, sex, socio-economic status, pubertal stage, family history of CVD and diabetes. In stratified analyses by age group, sex and country, similar strong patterns were observed. Later, it was reported that physical activity, CRF and fatness (skinfold and waist circumference) were all independently associated with clustered CVD risk (summed z-score of the CVD risk factors systolic blood pressure, triglyceride, total cholesterol:HDL ratio, HOMA score and aerobic fitness) in these children (Andersen et al., 2008). Results from a cohort study including 9- and 15-year-olds from all regions of Norway found that low muscle fitness is associated with clustered metabolic risk, independent of CRF, and after adjustment for age, sex, and pubertal stage. Independent of muscle fitness, an inverse association was found between $\mathrm{CRF}$ and clustered metabolic risk. Moreover, the OR for having clustered risk in the least fit quartile compared with the most fit quartile were 7.2 and 17.3 for muscle fitness and CRF, respectively. This study found that muscle fitness and CRF were independently associated with metabolic risk in youth (Steene-Johannessen, Andersen, Kolle, \& Andersen, 2009).

Changes in CRF are a significant predictor of changes in body fat percentage from childhood to adolescence, even after controlling for confounding factors such as physical activity, sex, and maturity (Ornelas, Silva, Minderico, \& Sardinka, 2011). A cohort study of Portuguese children show that while CRF significantly increased among boys and decreased in girls, the percentage of body fat decreased over time in boys and increased among girls. Alone, CRF explained 39, 26, and 25\% of the total variance in waist circumference, fat mass, and trunk skinfold, respectively. Adjusting for physical activity, sex, and maturation changes, CRF remained a significant predictor of these body composition variables.

Prospective observational analysis on the Danish cohorts showed that greater isometric strength of abdomen and back in youth is associated with lower levels of CVD risk factors in young adulthood independent of CRF, adiposity, sociodemographic and lifestyle factors (Figure 3). Each 1 SD difference in isometric muscle strength in youth was inversely associated with BMI, triglyceride, diastolic blood pressure, and a composite CVD risk factor score in young adulthood in multivariable adjusted analyses including CRF. Each 1 SD difference in isometric muscle strength in youth was significantly associated with 0.59 lower odds of general overweight/obesity in young adulthood and was marginally associated with incident raised of blood pressure, raised triglyceride and low HDL-C (Grøntved et al., 2013).

Lower isometric muscle strength and CRF in youth were also independently associated with adverse levels of fasting insulin, insulin sensitivity, and beta-cell function in young adulthood (Grøntved et al., 2013).

Improving CRF in children and adolescents has been studied especially in relation to school settings with limites effect for years. A simple way of getting a better CRF has been documented in Danish children in the EYHS. Active travel to school and to other activities provides an opportunity for daily physical activity and better CRF. Studying 919 nine and 15 year old children it was shown that the children and adolescents who cycled to school were significantly more fit than those who walked or travelled by motorized transport. They were nearly five times as likely (OR 4.8; 95\% CI 2.8-8.4) to be in the top quartile of fitness (Cooper et al., 2006). In a 6 year follow up study of the 9 year old children at baseline, it was shown that higher CRF was significantly associated with cycling to school in children and adolescents of both sexes. Longitudinal regression models showed that a change in travel mode from non-cycling to cycling was a significant predictor of CRF at follow-up $(\mathrm{p}<.001)$ after adjustment for potential confounders. Participants who did not cycle to school at baseline, but who had changed to cycling at follow-up, were significantly fitter $(0.33 \mathrm{~W} \mathrm{~kg}(-1))$ than those who did not cycle to school at either time point $(\mathrm{p}=.001)$, a difference of $9 \%$ was found (Cooper et al., 2008). 


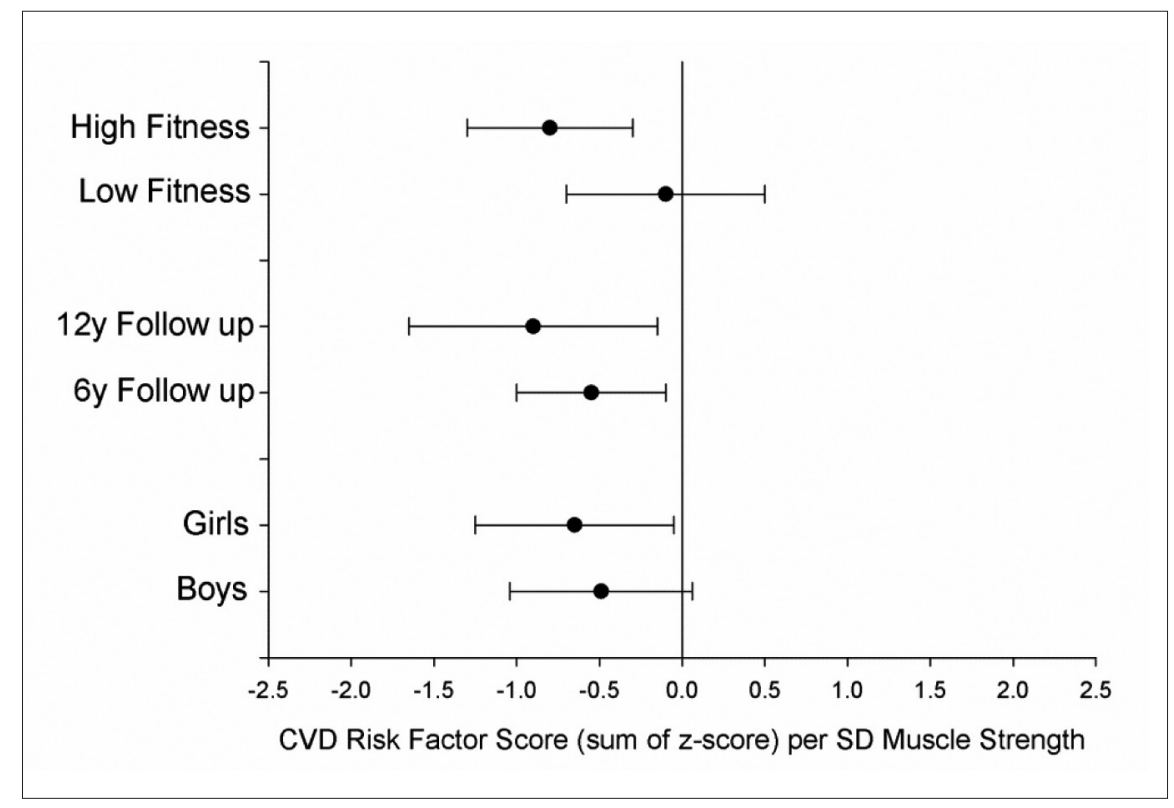

Figure 3. Isometric muscle strength in youth and composite cardiovascular risk factor score in young adulthood stratified by cardiorespiratory fitness (below and above the median, sex specific), follow-up time (6- or 12 years), and sex. Adapted from Grøntved et al. (2013)

In summary, low CRF is strongly associated with the clustering of CVD risk factors in children independent of country, age and sex. High levels of CRF are recognized to have wide ranging health benefits not only in terms of direct benefits observed in childhood, such as lower obesity risk and improved metabolic and vascular function, but also in terms of reduced disease risk in later life. The greatest benefit may be achieved when increasing CRF from low to moderate, mainly in those children and adolescents who are the least physically fit. Increasing CRF and muscle strength of abdomen and back should both be targets in youth prevention strategies to prevent insulin resistance and beta-cell dysfunction and improve CVD risk factors and body composition phenotypes in young adults. Commuting to school by cycling seems to be an easy and simple way of increasing CRF.

\section{CONCLUSIONS}

Key findings from both the cross-sectional and prospective observational data strongly suggest that sedentary behaviour, physical activity, cardio respiratory fitness, muscle fitness and muscle strength are relevant behaviours and attributes that influence several dimensions of health in children and adolescents, with latter influence on young adulthood.

Key findings so far from the EYHS can be seen below. Each of the exposures has some independent effects on different outcomes, and also combined effects that tend to have an increased magnitude, with a major contribution for the challenge that our society is currently facing, the battle against the ominous enemy of chronic disease. Reduced sedentary behaviour, and increased physical activity, CRF, muscle fitness and muscle strength may represent the common soil for a lifelong healthy life starting as early as in childhood.

\section{Sedentary behaviour}

- Correlates associated with sedentary behaviour are likely to differ from those associated with physical activity (PA).

- TV viewing and PA may be differently associated with adiposity and metabolic risk.

- Objectively measured time spend sedentary is associated with insulin resistance independent of overall and central body fat in 9-10-year-old children.

- Youth screen-time behaviour is associated with cardiovascular risk in young adulthood.

\section{Physical Activity}

- Frequency of outdoor play after school is a significant correlate for daily time in MVPA.

- PA levels should be higher than the current international guidelines of at least I hour per day of PA of at least moderate intensity to prevent clustering of CVD factors.

- Physical activity is inversely associated with insulin resistance in glucose-tolerant children.

- PA and CRF are separately and independently associated with individual and clustered metabolic risk factors in children. 


\section{Physical Fitness}

- Low CRF is strongly associated with the clustering of CVD risk factors in children and adolescents.

- Low muscle fitness is associated with clustered metabolic risk.

- Greater isometric strength of abdomen and back in youth is associated with lower levels of CVD risk factors and improved glucose metabolism and beta-cell function in young adulthood.

- Changes in CRF are a significant predictor of changes in body fat percentage from childhood to adolescence.

- Active commuting to school can significantly improve CRF.

Perspectives. A new EYHS project also including centres from Lithuania, Finland, Austria, Italy, Kosovo, and Hungary beside the old centres in Denmark, Norway, Ireland, Iceland and Portugal, will seek to identify childhood environmental, behavioural, biological, and genetic determinants of cardiovascular disease risk in childhood, adolescence and adulthood. It will provide new important surveillance data on behavioural, environmental, and biological risk factors for cardiovascular diseases among population-based samples of children and adolescents across all geographical regions of Europe.
The project will include population-based random samples of 9-year old children and 15-year old adolescents. From each country at least 1000 children and adolescents will be recruited, yielding a total sample size of at least 15000 children and adolescents. Furthermore, previous sampled participants from Denmark, Portugal, Norway, and Iceland have been followed up in adolescence or young adulthood (6- or 12-year follow-up), and will be followed up again with participants being 21-34-year of age (12- or 18-year follow-up).

The project - if supported through the Horizon 2020 program - will substantially expand the current knowledge of cardiovascular health status, and disparities herein, among diverse European children and adolescents and the extent that childhood and adolescent environment, lifestyle, biology, genetic make-up individually and jointly influence cardiovascular risk later in life.

Acknowledgements. The author is grateful to the participants and their families who gave their time to the study.

The Danish part of the work has been supported by the Danish Council for Strategic Research; The Ministry of Education; The Danish Heart Foundation; The Danish Health Fund (Sygekassernes Helsefond); and the foundation of Trygfonden.

\section{REFERENCES}

Adegboye, A. R., Anderssen, S. A., Froberg, K., Sardinha, L. B., Heitmann, B. L., Steene-Johannessen, J., Kolle, E., \& Andersen, L. B. (2011). Recommended aerobic fitness level for metabolic health in children and adolescents: a study of diagnostic accuracy. British Journal of Sports Medicine, 45(9), 722-728.

Andersen, L. B., Harro, M., Sardinha, L. B., Froberg, K., Ekelund, U. Brage, S., \& Anderssen, S. A. (2006). Physical activity and clustered cardiovascular risk in children: A cross-sectional study (The European Youth Heart Study). Lancet, 368(9532), 299-304.

Andersen, L. B., Sardinha, L. B., Froberg, K., Riddoch, C. J., Page, A. S., \& Anderssen, S. A. (2008). Fitness, fatness and clustering of cardiovascular risk factors in children from Denmark, Estonia and Portugal: The European Youth Heart Study. International Journal of Pediatric Obesity, 3 (Suppl. 1), 58-66.

Anderssen, S. A., Cooper, A. R., Riddoch, C., Sardinha, L. B., Harro, M., Brage, S., \& Andersen L. B. (2007). Low cardiorespiratory fitness is a strong predictor for clustering of cardiovascular disease risk factors in children independent of country, age and sex. European Journal of Preventive Cardiology, 14(4), 526-531.

Barker, A., Sharp, S. J., Timpson, N. J., Bouatia-Naji, N., Warrington, N. M., Kanoni, S., ... Langenberg, C. (2011). Association of Genetic Loci With Glucose Levels in Childhood and Adolescence: A Meta-Analysis of Over 6,000 Children. Diabetes, 60(6), 1805-1812.

Cooper, A. R., Wedderkopp, N., Han Wang, Andersen, L. B., Froberg, K., \& Page, A. S. (2006). Active travel to school and cardiovascular fitness in Danish children and adolescents. Medicine \& Science in Sports Exercises, 38(10), 1724-1731.

Cooper, A. R., Wedderkopp, N., Jago, R., Kristensen, P. L., Moller, N. C., Froberg, K., Page, A. S., \& Andersen, L. B. (2008). Longitudinal associations of cycling to school with adolescent fitness. Preventive Medicine, 47(3), 324-348.

den Hoed, M., Ekelund, U., Brage, S., Grontved, A., Zhao, J. H., Stephen, J., ... Ruth, F. J. (2010). Genetic 
Susceptibility to Obesity and Related Traits in Childhood and Adolescence. Diabetes, 59, 2980-2988.

Ekelund, U,, Anderssen, S. A., Froberg, K., Sardinha, L. B., Andersen, L. B., \& Brage, S. (2007). Independent associations of physical activity and cardiorespiratory fitness with metabolic risk factors in children: The European youth heart study. Diabetologia, 50(9), 1832-1840.

Ekelund, U., Anderssen, S., Andersen, L. B., Riddoch, C. J, Sardinha, L. B., Luan, J., ... Brage, S. (2009). Prevalence and correlates of the metabolic syndrome in a population-based sample of European youth. The American Journal of Clinical Nutrition, 89, 90-96.

Ekelund, U., Brage, S., Froberg, K., Harro, M., Anderssen, S. A., Sardinha, L. B., Riddoch, C., \& Andersen, L. B. (2006). TV viewing and physical activity are independently associated with metabolic risk in children: The European Youth Heart Study. PLOS Medicine, 3(12), e 488.

Ekelund, U., Luan, J., Sherar, L. B., Esliger, D. W., Griew, P., Cooper, A. (2012). International Children's Accelerometry Database (ICAD) Collaborators. Moderate to vigorous physical activity and sedentary time and cardiometabolic risk factors in children and adolescents. JAMA. 307(7), 704-712.

Ekelund, U., Sardinha, L. B., Anderssen, S. A., Harro, M., Franks, P. W., Brage, S., ... Froberg, K. (2004). Associations between objectively assessed physical activity and indicators of body fatness in 9- to 10-y-old European children: A population-based study from 4 distinct regions in Europe (the European Youth Heart Study). American Journal of Clinical Nutrition, 80(3), 584-590.

Froberg, K., Andersen, L. B. (2005). Mini Review: Physical activity and fitness and its relations to cardiovascular disease risk factors in children. International Journal of Obesity, 29, S 34-39.

Grøntved, A., Ried-Larsen, M., Ekelund, U., Froberg, K., \& Brage, S. (2013). Independent and Combined Association of Muscle Strength and Cardiorespiratory Fitness in Youth With Insulin Resistance and beta-Cell Function in Young Adulthood: The European Youth Heart Study. Diabetes Care, 36, 2575-2581.

Grontved, A., Ried-Larsen, M., Moller, N. C., Kristensen, P. L., Froberg, K., Brage, S., \& Andersen, L. B. (2013). Muscle strength in youth and cardiovascular risk in young adulthood (The European Youth Heart Study). British Journal of Sports Medicine, Mar 23 [Epub ahead of print].

Grøntved, A., Ried-Larsen, M., Moller, N. C., Kristensen, P. L., Wedderkopp, N. (2014). Youth screentime behaviour is associated with cardiovascular risk in young adulthood: the European Youth Heart Study. European Juornal of Preventive Cardiology, 21, 49-56.

Grøntved, A., Ried-Larsen, M., Froberg, K., Wedderkopp N., Brage, S., Kristensen, P. L., Andersen, L. B., \& Møller, N. C. (2013). Screen time viewing behaviors and isometric trunk muscle strength in youth. Medicine \& Science in Sports Exercises, 45(10), 1975-1980.

Jago, R., Page, A., Froberg, K., Sardinha, L. B., KlassonHeggebo, L., \& Andersen, L. B. (2008 a). Screenviewing and the home TV environment: The European Youth Heart Study. Preventive Medicine, 47(5), 525529.

Jago, R., Wedderkopp, N., Kristensen, P. L., Moller, N. C., Andersen, L. B., Cooper, A. R., \& Froberg, K. (2008 b). Six-year change in youth physical activity and effect on fasting insulin and HOMA-IR. American Journal of Preventive Medicine, 35(6), 554-560

Kelliny, C., Ekelund, U., Andersen, L. B., Brage, S., \& Loos, R. J. (2009). Common genetic determinants of glucose homeostasis in healthy children: The European Youth Heart Study. Diabetes, 58, 2939-2945.

Klasson-Heggebo, L., Andersen, L. B., Wennlof, A. H., Sardinha, L. B., Harro, M., Froberg, K., \& Anderssen, S. A. (2006). Graded associations between cardiorespiratory fitness, fatness, and blood pressure in children and adolescents. British Journal of Sports Medicine, 40(1), 25-29.

Laitinen, T. T., Pahkala, K., Magnussen, C. G., Viikari, J. S. A., Oikonen, M., Taittonen, L., ... Juonala, M. (2012). Ideal cardiovascular health in childhood and cardiometabolic outcomes in adulthood the cardiovascular risk in Young Finns study. Circulation, 125(16), 1971-1978.

Laitinen, T. T., Pahkala, K., Magnussen, C. G., Viikari, J. S. A., Oikonen, M. et al. (2012). Ideal cardiovascular health in childhood and cardiometabolic outcomes in adulthood: The cardiovascular risk in young finns study. Circulation, 125, 1971-1978.

Lawlor, D. A., Harro, M., Wedderkopp, N., Andersen, L. B., Sardinha, L. B. (2005). Association of socioeconomic position with insulin resistance among children from Denmark, Estonia, and Portugal: cross sectional study. BMJ, 23, 331(7510), 183.

Nichols, M., Townsend, N., Scarborough, P., Rayner, M. (2013). Cardiovascular disease in Europe: Epidemiological update. European Heart Journal, 34, 3028-3034.

Nichols, M., Townsend, N., Scarborough, P., Rayner, M. (2013). Trends in age-specific coronary heart disease mortality in the European Union over three decades: 1980-2009. European Heart Journal, 34, 3017-3027.

Nilsson, A., Andersen, L. B., Ommundsen, Y., Froberg, K., Sardinha, L. B., Piehl-Aulin, K., \& Ekelund, U. (2009). Correlates of objectively assessed physical activity and sedentary time in children: A crosssectional study (The European Youth Heart Study). BMC Public Health, 9, 322.

Ommundsen, Y., Klasson-Heggebo, L., \& Anderssen, S. A. (2006). Psycho-social and environmental correlates of location-specific physical activity among 9- and 15- year-old Norwegian boys and girls: The European 
Youth Heart Study. International Journal of Behavioral Nutrition and Physical Activity, 3, 32.

Ong, K. K., Elks, C. E., Li, S., Zhao, J. H., Luan, Ja. (2009). Genetic variation in LIN28B is associated with the timing of puberty. Nature Genetics, 41, 729-733.

Ornelas, R. T., Silva, A. M., Minderico, C. S., \& Sardinha, L. B. (2011). Changes in cardiorespiratory fitness predict changes in body composition from childhood to adolescence: Findings from the European Youth Heart Study. Physician and Sportsmedicine, 39(2), 78-86.

Ridgway, C. L., Brage, S., Anderssen, S. A., Sardinha, L. B., Andersen, L. B., \& Ekelund, U. (2011 a). Fat-free mass mediates the association between birth weight and aerobic fitness in youth. International Journal of Pediatric Obesity, 6(2-2), e 590-596.

Ridgway, C. L., Brage, S., Anderssen, S. A., Sardinha, L. B., Andersen, L. B., \& Ekelund, U. (2011 b). Do physical activity and aerobic fitness moderate the association between birth weight and metabolic risk in youth?: The European Youth Heart Study. Diabetes Care, 34(1), 187-192.

Ridgway, C. L., Brage, S., Sharp, S. J., Corder, K., Westgate, K. L., van Sluijs, E. M., ... Ekelund, U. (2011 c). Does birth weight influence physical activity in youth? A combined analysis of four studies using objectively measured physical activity. PLoS One, 6(1), e 16125 .
Ried-Larsen, M., Grontved, A., Froberg, K., Ekelund, U., \& Andersen, L. B. (2013). Physical activity intensity and subclinical atherosclerosis in Danish adolescents: The European Youth Heart Study. Scandinavian Journal of Medicine \& Science in Sports, 23(3), e 168-177.

Sardinha, L. B., Andersen, L. B., Anderssen, S. A., Quiterio, A. L., Ornelas, R., Froberg, K., Riddoch, C. J., \& Ekelund, U. (2008 a). Objectively measured time spent sedentary is associated with insulin resistance independent of overall and central body fat in 9- to 10-year-old Portuguese children. Diabetes Care, 31(3), 569-575.

Sardinha, L. B., Baptista, F., \& Ekelund, U. (2008 b). Objectively measured physical activity and bone strength in 9-year-old boys and girls. Pediatrics, 122(3), e 728-736.

Steene-Johannessen, J., Anderssen, S. A., Kolle, E., \& Andersen, L. B. (2009). Low muscle fitness is associated with metabolic risk in youth. Medicine and Science in Sports and Exercise, 41(7), 1361-1367.

van Sluijs, E. M., Page, A., Ommundsen, Y., \& Griffin, S. J. (2010). Behavioural and social correlates of sedentary time in young people. British Journal of Sports Medicine, 44(10), 747-755.

Wedderkopp, N., Froberg, K., Hansen, H. S., Riddoch, C., \& Andersen, L. B. (2003). Cardiovascular risk factors cluster in children and adolescents with low physical fitness: The European Youth Heart Study (EYHS). Pediatric Exercise Science, 15, 419-427. 